\title{
QUEEN'S
UNIVERSITY
BELFAST
}

\section{Northern Ireland and 'The Troubles', outlining an innovative approach to nursing/midwifery student teaching and module evaluation}

McMullan, J., Clarke, S. A., O'Hagan, M. T., O'Connor, T., \& Power, J. J. (2016). Northern Ireland and 'The Troubles', outlining an innovative approach to nursing/midwifery student teaching and module evaluation. Nurse Education Today, 37, e1-e4. https://doi.org/10.1016/j.nedt.2015.08.027

Published in:

Nurse Education Today

Document Version:

Peer reviewed version

Queen's University Belfast - Research Portal:

Link to publication record in Queen's University Belfast Research Portal

Publisher rights

(C) 2016 Elsevier. This manuscript version is made available under the CC-BY-NC-ND 4.0 license http://creativecommons.org/licenses/by-ncnd/4.0/ which permits distribution and reproduction for non-commercial purposes, provided the author and source are cited.

\section{General rights}

Copyright for the publications made accessible via the Queen's University Belfast Research Portal is retained by the author(s) and / or other copyright owners and it is a condition of accessing these publications that users recognise and abide by the legal requirements associated with these rights.

Take down policy

The Research Portal is Queen's institutional repository that provides access to Queen's research output. Every effort has been made to ensure that content in the Research Portal does not infringe any person's rights, or applicable UK laws. If you discover content in the Research Portal that you believe breaches copyright or violates any law, please contact openaccess@qub.ac.uk. 
Title

Northern Ireland and 'The Troubles', outlining an innovative approach to nursing/midwifery student teaching and module evaluation

\section{Authors}

Johanna McMullan The School of Nursing and Midwifery Queen's University Belfast

Susan .A. Clarke The School of Nursing and Midwifery Queen's University Belfast Marie Therese O'Hagan WAVE Trauma Centre, 5 Chichester Park South, Belfast Tony O'Connor The School of Nursing and Midwifery Queen's University Belfast John J. Power The School of Nursing and Midwifery Queen's University Belfast

Tel: Dr JJ Power 02890972392

e-mail: j.power@qub.ac.uk

\section{Key Words}

- Nursing

- Civil conflict

- Citizen trainers

- Pedagogy of discomfort 


\section{Introduction \& Background}

This paper addresses an innovative approach to teaching and evaluation of teaching to nursing and midwifery students, addressing sensitive social and political issues arising from civil conflict within their community of N. Ireland

'The Troubles' in Northern Ireland took place over an extended period with civil conflict particularly marked from the mid to late 1960's. The Troubles possibly resulted in the immediate death of some 3,800 people with estimates in excess of 40,000 having suffered severe injury. In addition, an indeterminate number of the citizenry suffered significant and ongoing psychological and subclinical symptoms as a consequence of the extremes of civil unrest. The legacy of 'The Troubles' is further reflected in disproportionately high levels of antisocial behaviour, family dysfunction, drug and alcohol dependency within the province (Wave 2014). WAVE, as an organisation, was formed in the early 1990 s and is a cross community voluntary organisation offering care and support to anyone bereaved, suffering trauma or injury as a result of the violent civil conflict.

A significant number of patients and clients that current nursing students will be attending to in the course of their nursing and midwifery training or subsequent to qualification, may present with primary or secondary conditions associated with their experiences of the conflict. Many of the students will be drawn from social and geographical areas previously impacted by 'The Troubles'. Therefore a joint educative initiative between the School of Nursing and Midwifery at Queen's University Belfast and WAVE was established to better inform nursing and midwifery students of the skills, knowledge and context required in working with those who have experienced trauma directly or indirectly as a result of the Northern Ireland conflict. As co-educators, WAVE delivered a core lecture (augmented by online material), which was then followed by tutorials with nursing and midwifery students. The tutorials were substantially led by those who had been involved with and experienced loss and trauma as a result of the conflict (Health Service users) and provided an opportunity to share their experience and their recollection of personal interactions with medical and nursing professionals. This approach is relatively unique in that it involves many of those directly involved with and injured by 'The Troubles' as 'citizen trainers' and clearly reflects the School's policy of progressively 
engaging with users and carers of nursing and midwifery services as co-educators to students.

Delivery of this teaching by WAVE forms part of the final phase of first year teaching in the Health and Wellbeing module. This module addresses the context of health; the anatomy and physiology of the body and human health (Life Sciences) but also the psychological, social, health education and public health dimensions of nursing and midwifery and the context of care.

Evaluative Aims were to evaluate the quality and clinical usefulness of teaching by the WAVE team to first year nursing students and involved piloting an innovative approach to evaluating part of the teaching module. Module evaluations are used to determine the quality of teaching and its impact as assessed by the nursing and midwifery students, with the intention to determine the standard and value of service delivery.

Methodologically a quantitative approach to audit and evaluation was undertaken in order to provide a breadth of understanding and insight to the student's experience and allow interpretation of the value to practice of the teaching delivery (Brown 2014).

An evaluative audit was undertaken with first year nursing students (adult field) after completion of the module, at the end of their first year of teaching and following the completion of two placements in clinical practice. The intention was to develop an audit tool that could be utilised for evaluating modules within the nursing and midwifery teaching program. Regard was given to the sensitivity of the issues (with the population of nursing students coming from diverse backgrounds) and how to better encourage an honest evaluation of the teaching and an individual evaluative method that might reduce the impact of peer influence. Three weeks were allowed to elapse from the delivery of teaching to the evaluation of this part of the module to better provide for qualitative reflection.

This study provides a descriptive survey of adult nursing student's perceptions of the WAVE teaching sessions following its inclusion in the Health and Wellbeing module within an undergraduate nursing programme. A convenience sample of first year 
adult nursing students $(n=80)$ were identified to complete a questionnaire and the evaluation was completed by 66 students $(n=66)$

The student's opinion was investigated by means of a questionnaire and comprised seventeen questions using Likert type Scales. Questions were designed to seek the student's views on (1) the importance of inclusion of the topic on the UG curriculum, (2) the usefulness of lecture material, (3) the value of including survivors in delivery of the material, (4) the impact of the material and (5) requirements for further content (the five areas). Parahoo (2014) suggests that ease of analysis and the high degree of reliability makes questionnaires suitable for this type of research where data is being sought from a large number of individuals at one time.

In an attempt to encourage a good response rate, the questionnaire was conducted as part of the module review in the last lecture of the module during the last week of the final phase. It was a convenient time and location for potential respondents.

The questionnaire was constructed using a five point Likert type scale (ranging from "strongly agree" to "strongly disagree" and an "undecided" option, with a few yes /no answer questions. In order to facilitate such a large group, to ensure confidentiality, ease of collation of data and to reduce completion time the Personal Response System (PRS) was used.

Validity and Reliability was reflected in the design of the questionnaire in terms of both content and its construct validity (Parahoo 2014). It was reviewed by colleagues experienced in this area of questionnaire development and piloted with previous student cohorts.

Ethically some of the nursing student population may have found the subject area covered by the WAVE sessions challenging, from their background and life or family experience. The issue of teaching to a particularly challenging area was addressed sensitively throughout, with support measures in place, and the students were under no obligation to take part in the module evaluation.

Data Analysis involved instantaneous responses. Subsequently the results were analysed using the PRS software. 
Results from each of the five areas were assessed by multiple questions and there was close agreement of responses suggesting good construct validity. In response to questions seeking views on the importance of including Troubles-related teaching on the curriculum (Appendix Figure 1) 74\% of respondents agreed or strongly agreed that it was important. Eleven (13\%) did not think it should be included in the curriculum.

Overall, the students rated the teaching highly, especially the open and informal approach to the sessions which they felt made their experiences real to them (91\% agreed/strongly agreed); with 68-88\% agreeing or strongly agreeing that the lecture material was informative and had increased their knowledge and understanding (Appendix Figure 1). Only 12(13\%) felt the lecture material was not useful or informative.

When asked if the issues of victim's/survivors should be studied by nursing and midwifery students 74\% agreed/ strongly agreed; the group also firmly believed that nursing and midwifery students should be taught about "Troubles" related trauma and health related issues, with again less than $11 \%$ disagreeing or strongly disagreeing. It is unsurprising therefore that the group reported positively that the sessions had helped them learn how people are affected by trauma/conflict (91\% agreed/ strongly agreed). Responses to the statement "It has made me think more about how issues of trauma may impact on my patients" yielded the most positive response (92\% agreed/strongly agreed) and the students believed they were more aware of the relevance of victims and survivors health issues due to the lectures/tutorials (85\% responding positively).

Overwhelmingly, the students appreciated the contribution of the citizen trainers; 88 (91\%) agreed or strongly agreed that their humour, honesty and informal approach enhanced the sessions and although 2(6\%) disagreed no-one strongly disagreed with this concept (Figure 1).

The majority of students (82\%) also agreed that "This teaching will equip me for dealing with any issues regarding victims and survivors that arise in nursing or midwifery practice" however 84\% agreed or strongly agreed that further information on how to provide support and where to refer patients would be useful, perhaps therefore implying that the group felt this teaching had raised their awareness of the 
issues but not to the point where they believed they could provide all the support their patients would or might require which is understandable.

When asked to assess the impact of the teaching sessions on their learning and practice (Appendix Figure 4) the majority 85 (92\%) agreed or strongly agreed that they were now more aware of related health issues and how this might impact on their patients. Most (82\%) also agreed that the teaching would equip them for dealing with such issues in their future practice. Interestingly, only $60 \%$ felt that the teaching had changed their views.

Finally, the students were asked if further information or time for the sessions was required (Appendix Figure 5) - 64\% would have liked more information on the history of 'The Troubles' and 74\% would have liked more information on how to provide or refer patients for psychological support implying that the group felt this teaching had raised their awareness of the issues but not to the point where they could provide all the support their patients might require which is also understandable. Only $19 \%$ wanted more time on the subject and anecdotal evidence from the students seems to suggest that a number of them thought the sessions were "emotionally exhausting" with one student observing "It was so worthwhile and really made me think, but I didn't enjoy it, it wasn't easy listening and I couldn't have taken much more".

\section{Discussion}

In Northern Ireland there remains a tendency toward avoidance of or discomfort with discussion of sensitive issues associated with 'The Troubles: there are often strongly held emotional attachments for many in the local society or sense of fear (Jordon et al.2007; Coulter et al. 2012).

The importance of development of Cultural Competence has been discussed by Coulter (2012) in regard to Social Work students and applies equally within nursing student training with an acknowledgement/better understanding of the lived experience of those individuals accessing health services that have been directly affected by 'The Troubles'. While largely welcomed and valued by the students themselves as an area of study, the chosen pedagogy nonetheless 
requires careful consideration and planning of how best to facilitate deep learning while supporting all involved.

The advantage of what Boler and Zembylas (2003) call 'pedagogy of discomfort' is that student learning in this emotionally charged area is enhanced as a result of the student leaving their comfort zone within the safe atmosphere of the learning environment. Testing the boundaries of personal beliefs, values and perceptions is facilitated through exploration of the experiences of victims and survivors of 'The Troubles' to enhance deep learning; at times this involved those perceived as belonging to the 'other side' in terms of cultural backgrounds in Northern Ireland.

Most of the students appreciated the value and relevance of the subject area in relation to their nursing studies and the remaining students' responses may reflect a wish to 'move on' in a post conflict society. However, effective care is inextricably linked to an understanding of the impact of this period on those involved, and for whom 'moving on' is often not an option.

Preparation and delivery of the sessions involves a high emotional investment on the part not only of the WAVE volunteers in delivering the sessions and relaying their lived experiences, but also by students and school lecturers. Informal debriefing at the end of the sessions included thanking the students for their participation and providing students with information on support and counselling available.

\section{Conclusion}

If nurses are to adequately respond to the existing and future needs of victims/survivors of the conflict in Northern Ireland it is essential that they gain cultural competence by addressing issues of sectarianism within their training context (Coulter et al. 2012). From the volunteer's point of view, there is clearly a benefit in having nursing professionals with a knowledge and understanding of the effect of the conflict on health in a broad context of different communities in Northern Ireland. Benefits are also evident in terms of appreciating the impact on the health of individuals who are victims and survivors of the violence of this past. Evidence from 
this small study suggests students were engaged and experienced deep learning due to the innovative pedagogical approach of face-to-face interaction within small groups and within a safe environment (Boler and Zembylas 2003). It is of course also imperative that measurers are put in place to provide ongoing support or information for anyone involved.

This study suggests that the benefits greatly outweigh the effort required to reap such positive results in terms of engagement, learning and understanding. This study echo's other research findings that emphasize the contribution of service user and carer representatives to enable students to understand key concepts at a meaningful level (Coulter et al. 2012), which might not be achieved in traditional teaching settings. 


\section{Reference List}

Boler, M. and Zembylas, M. (2003) Discomforting truths: The emotional terrain of understanding differences. In P. Tryfonas (ed.) Pedagogies of Difference: Rethinking Education for Social Justice, pp. 110-36. New York: Routledge .

Brown S. (2014) Learning, Teaching and Assessment in Higher Education. Basingstoke: Palgrave Macmillan

Coulter, S., Campbell, J., Duffy, J. and Reilly, I. (2012) 'Enabling social work students to deal with the consequences of political conflict: engaging with victim/survivor services users and a pedagogy of discomfort', Social Work Education, [Online] Available at:

http://www.tandfonline.com/doi/abs/10.1080/02615479.2012.668180

Jordan J. Lynch U. Moutray M. O'Hagan M. Orr J. Peake S. and Power J. (2007) Using Focus Groups to Research Sensitive Issues: Insights from Group Interviews on Nursing in the Northern Ireland "Troubles". International Journal of Qualitative Methods 6:(4):1-19.

Parahoo K. (2014) Nursing Research Principles Process and Issues (3rd edition) Basingstoke: Palgrave Macmillan

Repper J. and Breeze J. (2006) User and carer involvement in the training and education of health professionals: A review of the literature. International Journal of Nursing Studies. 44: 3: 511-519

WAVE (2014) Transgenerational Trauma and Dealing with the past in Northern Ireland. Available @ http://www.wavetraumacentre.org.uk/uploads/pdf/1404220890-100105-WAVE-transgen-report.pdf (accessed 23 2015) 


\section{Appendix}

Nursing and Midwifery students should be taught about Troubles related trauma and health related issues.

1. Strongly disagree

2. Disagree

3. Neither agree or disagree

4. Agree

5. Strongly agree

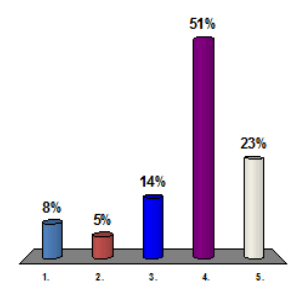

The open and informal approach to the tutorials and listening to victims/survivors stories face-to-face make their experiences real

1. Strongly disagree

2. Disagree

3. Neither agree or disagree

4. Agree

5. Strongly agree

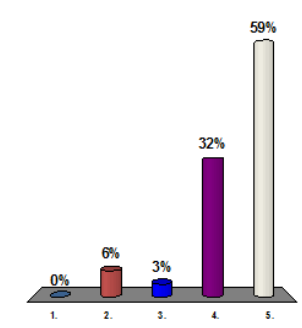

Additional time in the tutorials, particularly for questions would have been useful.

1. Strongly disagree

2. Disagree

3. Neither agree or disagree

4. Agree

5. Strongly agree
The lecture increased my knowledge and understanding of trauma and conflict in Northern

$$
\text { Ireland }
$$

1. Strongly disagree

2. Disagree

3. Neither agree or disagree

4. Agree

5. Strongly agree

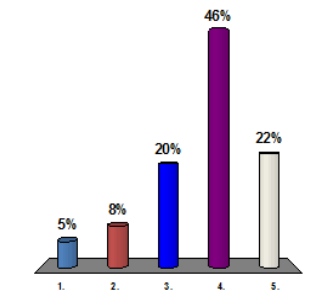

This teaching will equip me for dealing with any issues regarding victims and survivors that arise in nursing or midwifery practice.

1. Strongly disagree

2. Disagree

3. Neither agree or

disagree

4. Agree

5. Strongly agree

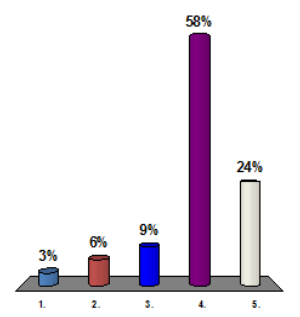

Figure 1. Examples of student responses to questions related to five areas of assessment; the importance of teaching 'Troubles' related issues in the curriculum, usefulness of teaching material, contribution of Survivors/citizen trainers in teaching, the impact of teaching and requirements for additional teaching. 